\title{
Age and arousal in the rat
}

\author{
EUGENE R. DELAY \\ Regis College, Denver, Colorado \\ and. \\ WALTER ISAAC \\ University of Georgia, Athens, Georgia
}

\begin{abstract}
The influence of illumination level on locomotor activity and reaction times of three age groups (25, 90, and 180 days old) of rats was studied. Age-related differences were obtained, and consistent effects on the two behavioral measures were obtained for the individual animals.
\end{abstract}

Ambient illumination has been found to exert a significant effect upon reaction times (Hornbuckle, 1972) and locomotor activity of monkeys (Isaac \& Troelstrup, 1969). Both of these studies reported that ambient illumination had opposite effects in nocturnal and diurnal monkeys, with nocturnal monkeys having shorter reaction times and more activity in the dark. In the nocturnal rat, light has been shown to have a depressant effect on locomotor activity (Isaac, 1971), similar to that seen in nocturnal monkeys. In these studies, it was assumed that changes in behavior were the consequence of an altered arousal level produced in the subjects by manipulating the ambient sensory environment and that each behavior was similarly affected (French, Van Amerongen, \& Magoun, 1952; Starzl, Taylor, \& Magoun, 1951). That is, arousal level was the relevant variable, but the behavioral measure used to indicate arousal level was not critical. Such an assumption of generality is necessary if the concept of arousal is to be of predictive value.

An important dimension limiting the generality of the results obtained in previous studies is related to the age of the subjects studied. Kallman and Isaac (1975) reported that 30-day-old rats showed a greater illumination effect upon their activity than did rats 150 days old. Delay (1981), on the other hand, found that 90-day-old rats showed a greater light-dark difference in activity levels than did rats 35 days old. However, different animal strains were used in these studies, making interpretation difficult.

The present study investigated these two variables, the constancy of arousal level across two different tasks and across three different age levels.

E. R. Delay's mailing address is: Department of Psychology, Regis College, Denver, Colorado 80221. W. Isaac's mailing address is: Department of Psychology, University of Georgia, Athens, Georgia 30602.

\section{METHOD}

\section{Subjects}

Twenty-one male albino rats (Biological Research Laboratories) were housed individually and were adapted to the colony for at least 4 days before being placed on water deprivation. Three age groups of seven animals each were placed on water deprivation at the ages of 25,90 , and 180 days, respectively. Food was available in the home cage ad lib throughout the study. Colony lighting was maintained on a 12-h-on/12-h-off schedule, with the lights coming on at 8:00 a.m. All testing occurred between 3:00 p.m. and 6:30 p.m., with the time of testing being held constant for the individual animals.

\section{Apparatus}

Reaction times and activity measures were obtained in a soundattenuated chamber with the interior painted white and with inside measurements of $50 \times 50 \times 75 \mathrm{~cm}$. The door of the chamber contained a $16 \times 16 \mathrm{~cm}$ double-pane acrylic (Acryglaze) observation window covered with cheesecloth on the outside. A fluorescent light was mounted on the ceiling of the chamber directly over the test apparatus. A ventilation fan provided $48-\mathrm{dB}$ ambient masking noise on the A scale and 16-17 dB at $4 \mathrm{kHz}$ (re: $20 \mathrm{microN} /$ $\mathrm{m})$, as measured by a Bruel and Kjaer SPL meter (Type 2203) with an octave filter set (Type 1613).

The reaction time stimulus was a 4-kHz tone (Delay, Golden, \& Steiner, 1978) $20 \mathrm{~dB}$ above the background noise at $4 \mathrm{kHz}$. To obtain reaction times, the rats were placed in a $15 \times 15 \times 25 \mathrm{~cm}$ cage centered in the chamber. The cage was constructed of .5-in. hardware cloth, except for one end made of .25 -in. plywood with a 4-cm-diam hole centered $2.5 \mathrm{~cm}$ above the floor. A translucent, acrylic response panel, $1.5 \mathrm{~mm}$ thick, was suspended by a hinge on the outside of the plywood wall over the hole. The panel was dimly illuminated at all times by a green light-emitting diode (LED: FLV340) located $2.5 \mathrm{~cm}$ behind the panel. A logic signal was produced by panel movement of $2 \mathrm{~mm}$, which interrupted a beam between an infrared LED (FPE104) and a phototransistor (FPT120). A reinforcer pedestal was located $5 \mathrm{~cm}$ to the left of the center of the response panel. A solenoid valve, located inside the chamber, delivered a measured quantity of water through the pedestal and produced an auditory signal of the water's presence.

To measure locomotor activity, each animal was placed in a $23 \times 20 \times 36 \mathrm{~cm}$ long glass container, clear except at the bottom, which was painted gray, and a cover made of .5-in. hardware cloth was placed on top. An infrared light beam (FPE104) bisected the length of the container $2 \mathrm{~cm}$ above the floor and projected onto a phototransistor (FPT120). When the rat crossed through the beam, a count was registered. All solid-state programming and recording equipment was located in another room. 


\section{Procedure}

The rats were tested for a total of 20 days, with the first 10 days being devoted to training and habituation to the equipment and handling procedures and the last 10 days being devoted to obtaining data for analysis. Both reaction time and locomotor activity were measured each day throughout the experiment. All subjects were water deprived for $22.5 \mathrm{~h}$ before the reaction time task and were allowed access to water for $10 \mathrm{~min}$ immediately following the task. Then $30 \mathrm{~min}$ was allowed for fluid absorption before activity measurement began. The short time period between the two tasks and rigid adherence to a daily testing schedule reduced potential circadian rhythm effects. All subjects were given access to water for an additional $10 \mathrm{~min}$ following the measurement of locomotor activity. Although light $(1400 \mathrm{~lx})$ and dark $(<.5 \mathrm{~lx})$ conditions were alternated daily, sensory conditions were the same for both tasks on any given day.

By the 6th day of training, all rats were being trained on the final reaction time procedures. At that point, short response times were selectively reinforced by varying the duration of the tone, including durations that were too short to allow a response to occur $(0.2,0.5,0.8,1.1,1.4$, and $1.7 \mathrm{sec})$, and by reinforcing only those responses that were made during the presence of the tone. Each of the six stimulus durations was presented eight times during a test session, with the order of presentation counterbalanced by a Latin square design and with a different Latin square being used each day. Interstimulus intervals were varied randomly with a mean of $30 \mathrm{sec}$. Ten preliminary trials extending over a 6-min period, not included in the analysis, were given each day using the longest tone duration to ensure stable responding. Reaction times of $10 \mathrm{sec}$ or less to the tone's onset were recorded on each trial. All response latencies greater than $10 \mathrm{sec}$ were recorded as nonreaction time responses. To maintain stimulus control, a 10-sec time-out was imposed if a response was made within a 10-sec period prior to the onset of the tone.

When locomotor activity was measured, the rats were allowed a 6-min period, not included in the analysis, to adapt to the sensory condition. Both tasks, then, extended over a period of $30 \mathrm{~min}$, with data being gathered during the last $24 \mathrm{~min}$ of the period.

\section{RESULTS}

The six shortest reaction times for each rat in each experimental session were used in all analyses (Isaac, 1960). An analysis of variance with appropriate error terms for independent measures (three age levels) and related measures (two illumination conditions) was performed. It showed that age-related differences in reaction times were significant $[F(2,18)=$ $10.99, \mathrm{p}<.005$ ], as were the effects of illumination conditions $[F(1,18)=43.64, p<.001]$. The interaction between the age levels and the illumination conditions was also significant $[\mathrm{F}(2,18)=3.94, \mathrm{p}<.05]$. Reaction times of all the age levels were shorter in the dark, with the oldest animals having the longest response latencies and the middle age group having the shortest (Figure 1).

A similar analysis of variance was used to evaluate the effects of illumination upon the locomotor activity of the age groups. Again, the differences related to age were found to be significant $[F(2,18)=$ $12.78, \mathrm{p}<.0011$, as were the differences related to illumination conditions $[\mathrm{F}(1,18)=415.79, \mathrm{p}<.001]$. The interaction between age levels and illumination conditions was also significant $[F(2,18)=5.80, p<$

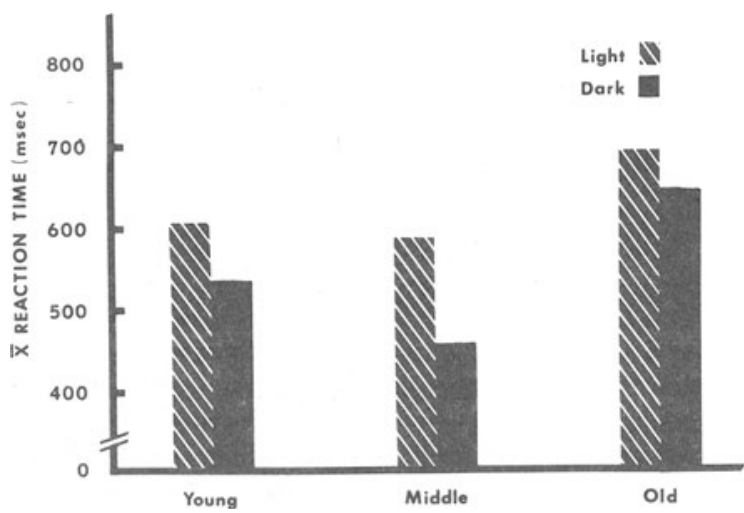

Figure 1. Mean reaction times as a function of age and illumination condition.

.025]. In all age groups, the greater activity levels were seen in the dark, with the oldest animals being the least active and the middle age group being the most active (Figure 2).

Thus, it is apparent that the illumination conditions had a significant effect upon both reaction times and locomotor activity; the levels of age that were studied were also a significant determiner of both reaction times and locomotor activity. The relationships of the means were similar for both measures. However, in neither task were illumination effects independent of the age levels studied.

To explore further the differences among the age levels, correlations were calculated for each behavior in the light and dark for each age level. The correlations between reaction times in the light and the dark were significant for the oldest animals $\operatorname{lr}(5)=$ $.95, \mathrm{p}<.005]$ and for the middle age group $[\mathrm{r}(5)=$ $.67, \mathrm{p}<.05]$, but not for the youngest animals $[\mathrm{r}(5)$ $=.32]$. Similar results were seen when activity scores

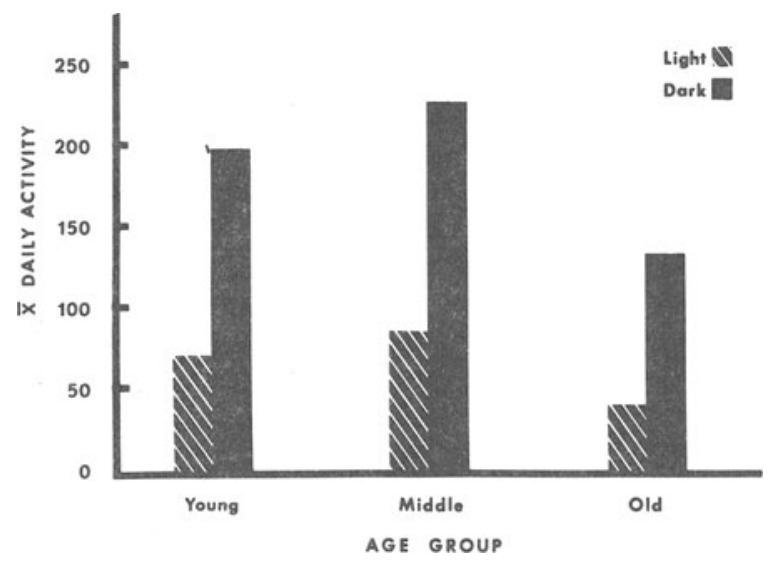

Figure 2. Mean daily activity levels as a function of age and illumination condition. 
were examined. The correlations between light and dark activity scores were significant for the oldest rats $[r(5)=.83, p<.025]$ and the middle age group $[\mathrm{r}(5)=.77, \mathrm{p}<.025]$, but not for the youngest animals $[\mathrm{r}(5)=.50]$. These correlations indicate that the consistency of both behavioral measures increased with age under each illumination condition.

In addition, the reaction time scores were correlated with the activity scores in the light and dark for the individual age groups. The oldest animals exhibited significant correlations for reaction times and activity in the light $[\mathrm{r}(5)=-.89, \mathrm{p}<.005]$ and dark $[r(5)=-.77, p<.025]$. Similar negative correlations were also found to be significant for the middle age group in the light $[\mathrm{r}(5)=-.85, \mathrm{p}<.01]$ and dark $[\mathrm{r}(5)=-.85, \mathrm{p}<.01]$. In the youngest group of animals, the correlations between the two measures were negative but nonsignificant in both the light $[\mathrm{r}(5)=-.45]$ and the dark $[\mathrm{r}(5)=-.56]$. Again, the older subjects showed the greatest consistency.

\section{DISCUSSION}

It is apparent that the illumination conditions had a significant effect upon both reaction times and levels of locomotor activity; the levels of age that were studied also influenced both behavioral measures studied. The relationships of the means on both measures were similar under both sensory conditions and at all age levels studied. The magnitude of the effects of the ambient sensory conditions is not, however, independent of the animal's age. These data would seem to resolve the apparent discrepancy in the age-related differences in the magnitude of illumination effects on behavior seen in the earlier studies (Delay, 1981; Kallman \& Isaac, 1975) and support the notion that the effect of ambient sensory stimulation on behavior is age dependent.

Because of the consistency of the subjects' performance on the two different behaviors studied, it would seem justifiable to speculate that there is an underlying function being manipulated by varying ambient sensory environments. The notion that arousal level can be manipulated by varying ambient illumination has been proposed elsewhere (Isaac \& Devito, 1958). The use of the concept of arousal as an explanatory concept in discussing the effects of varying sensory conditions upon a variety of behaviors is supported by the data obtained in the present study. Furthermore, the present data also suggest that the arousal level obtained under similar conditions differs among animals but is consistent for each age group and for each animal across behavioral measures. Such results are supportive of the role proposed for arousal level by Hebb (1955) many years ago.

\section{REFERENCES}

Delay, E. R. Effects of illumination on activity following superior colliculus and caudate lesions in young and older rats. Physiology \& Behavior, 1981, 27, 673-682.

Delay, E. R., Golden, A. J., \& Steiner, N. O. A compact IC tone generator. Physiology \& Behavior, 1978, 21, 133-134.

French, J. F., Van Amerongen, F. K., \& Magoun, H. W. An activating system in brain stem of monkey. Archives of Neurology and Psychiatry, 1952, 68, 577-590.

Hebs, D. O. Drives and the CNS (conceptual nervous system). Psychological Review, 1955, 62, 243-255.

Hornbuckle, P. A. Delayed response performance as a function of sensory stimulation in the squirrel and owl monkey. Journal of Comparative and Physiological Psychology, 1972, 79, 99-104.

IsAAc, W. Arousal and reaction times in cats. Journal of Comparative and Physiological Psychology, 1960, 53, 234-236.

IsAAc, W. A study of the relationship between the visual system and the effects of d-amphetamine. Physiology \& Behavior, 1971, 6, 157-159.

IsAAC, W., \& Devito, J. L. Effect of sensory stimulation on the activity of normal and prefrontal-lobectomized monkeys. Journal of Comparative and Physiological Psychology, 1958, 51, $172-174$.

IsAac, W., \& Troelstrup, R. Opposite effect of illumination and d-amphetamine upon activity in the squirrel monkey (Saimiri) and owl monkey (Aotes). Psychopharmacologia, 1969, 15, 260-264.

Kallman, W. M., \& IsAac, W. The effects of age and illumination on the dose-response curves for three stimulants. Psychopharmacologia, 1975, 40, 313-318.

Starzl, T. E., TAYlor, C. W., \& Magoun, H. W. Collateral afferent excitation of reticular formation of brain stem. Journal of Neurophysiology, 1951, 14, 479-496.

(Manuscript received for publication May 20, 1983.) 